\title{
An extensive analysis of optimal suppliers with better purchasing period for customers in web based material demand aggregation
}

\author{
Tatavarthy Srinivas Rao Balkrishna Rao, Dr. N. V. R. Naidu and Dr. K. Mallikharjuna Babu
}

\begin{abstract}
In today's modern trading world, web based material demand aggregation has emerged as a significant and lively research front in the supply chain management. In common, the Demand Aggregation technique synchronizes and unites the requirements of the buyers with the active participation of a web based agent to offer a lucid depiction of purchasing requests throughout the enterprise. The objective of utilizing material demand aggregation is to offer services to all the buyers (manufacturers) in a cost effective manner. The web based agent is responsible for fulfilling this ultimate goal of web based material demand aggregation. It discovers the optimal suppliers who can supply the raw materials in a cost effective manner as manufacturers may require raw materials in different quantities and different suppliers are likely to offer materials at different slab rates. Moreover, the dilemma of web based agent increases as each manufacturer may require the raw materials at different instants of time. If the web based agent works only with the intention of enjoying more slab rates, it drives all the manufacturers to purchase at a single instant of time, on account of which some of the manufacturers will be affected because of high inventory costs incurred. Equally, if the manufacturers are suggested to purchase the materials just in time to avoid the inventory costs, they will miss the offer of slab rates leading to high purchasing cost. Thereby, we propose an analytical model which will pin down the optimal period of purchasing for all the manufacturers so that they can avoid the high inventory cost incurred and can also enjoy a good slab rate. With the aid of the proposed analytical model designed to achieve optimal purchasing period, the web based agent can guide all the manufacturers to purchase the required raw materials in a cost effective manner.
\end{abstract}

Index Terms - Aggregated Demand, Analytical Model, Material Demand Aggregation, Optimal Suppliers, Slab Rate, Web Based Agent.

\section{INTRODUCTION}

Due to the global competition, the vastly changing market, shorter product life cycles, vibrant changes of demand patterns and product varieties and environmental standards has produced demands for manufacturing enterprises to skillfully survive [1] all through the last decade.

Tatavarthy Srinivas Rao Balkrishna Rao, Assistant Professor, Amrita School of Engineering, Amrita Vishwa Vidyapeetham, Bangalore, Karnataka, Pincode: 560035, India. Phone: +91 9845662109 Email: (tatavarthy_66@yahoo.co.in, tatavarthysrinivasraophd@gmail.com).

Dr. N. V. R. Naidu, Prof \& HOD, Department of IEM, M S Ramaiah Institute of Technology, Bangalore, India. Email: nvrnaidu@gmail.com.

Dr. K. Mallikharjuna Babu, Principal, BMS college of Engineering, Bangalore, India. Email: drkmbabu@gmail.com.
The very important decision which companies meet on a usual basis is the classification of products and/or raw materials. Excess inventories that are costly or scarce inventory that cannot meet its customer demands are the result of poor decisions [2]. The following signify the confronts faced by the organization rapidly namely the globalization of commerce, global distribution of manufacturing and warehousing facilities, rapid commoditization of products, demand for customized products, competitive pressures, rapid advances of information technology. Due to the above mentioned features [4] the business organizations are enforced to consider on their supply chains.

It has been defined by Lee and Billington [4] that the supply chain is a system of facilities that do the functions of the procurement of material, transformation of material to intermediate and finished products, and the deliverance of the finished products to customers. In the other way supply chain may be defined as an incorporated process concerning a number of diverse business units (i.e., suppliers, manufacturers, distributors, and retailers) working together to (1) acquire raw materials, (2) convert these raw materials into mentioned final products, and (3) give out these final products to retailers [5]. The three sections of a supply chain observed from a process outlook are sourcing or procurement, manufacturing and distribution, and inventory disposal. The factors that manipulate this tremendously pulsating setting are supply availability as well as market fluctuation. At the same time, the communications among the entities, the length of the supply chain, the lead times of manufacturing as well as shipping, the complexities of modeling the individual entities, the stochastic nature of the demands, etc produce problems which are frequently exceedingly huge and multifarious [2]. The organization of the flows of materials and information among suppliers, manufacturers and customers, and achievement of product delaying and mass customization in the supply chain is involved in a soundly incorporated supply chain [7]. It has been mainly studied in isolation by the researchers and practitioners for several years [5] about the diverse processes of the supply chain.

The necessary for group effort of the manufacturers along with the service providers with their suppliers to progress their purchasing and supply management functions from a clerical role to an essential part of a new phenomenon known as supply chain management was sought in the year 1990 after by several manufacturers and service providers [7]. In 
the supply chain management various organizations with different objectives are well coordinated and integrated towards a universal goal in supply chain management [5]. This involves several processes [6] including the setting up for acquiring materials, collecting of finished products from these materials and delivery of products to customers. In the theory of the supply chain management [3] a wide range of activities that support the planning, implementation and control manufacturing and the delivery processes right from the source of raw material to the place where the end product is consumed are combined. With the aid of the improved supply chain management [9] it is possible to minimize the product costs significantly at the same time as sustaining outstanding product quality and customer services.

The main objective of the supply chain management is more efficient fulfillment of customer's demand. For a manufacturing venture, it is precisely, to build the right product, for the precise customer, in the exact amount, at the correct time [9]. In the Supply Chain Management (SCM) the issues where the decisions of supply, production and demand are incorporated in a single framework are taken into account. By a traditional supply chain certain factors which are encountered are supply, production and demand. Due to the globalization of demand-supply networks as well as the need for a more integrated operation plan, demand planning is one of the best confronts implemented to the manufacturers in recent days. For the well-organized management of the demand variability [10] suitable demand aggregation and statistical forecasting are the renowned approaches. Under tentative business environment the necessary process, Material Demand Aggregation in the organization and optimization of supply chains enormously manipulate the prosperity of a firm. Generally, all through the enterprise this process keeps track of purchasing requests by classifying and combining the requirements.

So as to provide the management with the required information to assess purchasing practices and trends, the historical purchasing data is examined by demand aggregation. The aggregation of demand provides advantages through the improved quality management information. On behalf of additional proficient dealings with markets and better value for money, combining, or coordinating demand information together inside as well as among public sector organizations is very important. To optimize the buying strength Demand Aggregation results in high savings on the cost of direct and indirect goods and the services which make use of automatic workflow and a supple Request for Quote (RFC) management as the diverse departments or the companies of the enterprise are assisted. A single purchasing request is attained by the collection of the product demand across multiple plant locations, distribution channels or other units of the enterprise, which is ordered from restricted set of suppliers at the same time as following the standardized purchasing procedures. With the aid of the Demand Aggregation the companies are supported to increase their purchasing power and achieve larger savings on the costs of goods as well as services by the information and visibility of the purchasing requests throughout the entire company offered to the businesses.

Even supposing the incoming orders are relatively constant the real end consumer demand may cause a variation in the order inter-arrival time. At the same time, for the period of lead time, an accurate estimation of mean and variance of the demand by the suppliers facing discrete demand is not probable. To lessen this problem [14] aggregating demand data into larger time units might be valuable. A course of action can be developed in such a manner meets the business goals efficiently by undertaking the processes that alleviate the aggregated demand and supply [15]. All the supply chain stages have to work in mutual aid with a combined plan [16] with the intention of optimizing the supply chain performance.

Yet, it is compulsory to select a most favorable set of suppliers who can supply the ideal set of item while obtaining a set of items from different suppliers who may sell only a subset (bundle) of a preferred set of items. Optimal suppliers faces more complexity in the material demand aggregation because of the fact that the huge numbers of suppliers, each supplier providing different materials make this process of selecting the most favorable suppliers. For few quantities of every material as well every supplier provides a different slab rates.

In spite of all the aforementioned difficulties in this selection of optimal suppliers, in the case of web based material demand aggregation, the selection of the optimal suppliers for all the buyers is the responsibility of a web based agent who comes across problems. The dilemma again arises since requirement instance (or date) of each manufacturer varies. In detail, each manufacturer needs each raw material at different instances. If the web based agent suggests all the manufacturers to purchase all the raw materials in same instance to get the benefit of high slab rates, some of the manufacturers may suffer because of high inventory costs. To avoid the loss of high inventory, if the web based agent suggests the manufacturers to follow just in time inventory, some manufacturers may miss the offer of slab rate benefits. Again the web based agent has to take the responsibility of selecting the optimal period of purchasing so that the most of manufacturers don't get affected because of high inventory cost as well as losing of slab rate benefits.

In this paper we are proposing an analysis which will support the web based agent in selecting the optimal period of purchasing of raw materials, for all the manufacturers so that the agent can work actively in the web based material demand aggregation by providing cost effective raw materials to all the manufacturers with an optimal slab rate. The analysis we have proposed here utilizes the optimal supplier analysis in web based agent [20] as a supporting base. The remaining part of paper is organized as follows; Section 2 contains some existing relevant works done so far in the domain of material demand aggregation and section 3 constitutes the proposed analysis with required illustrations and different stages of analysis. Section 4 gives out the implementation results and section 5 concludes the paper. 


\section{RELATED WORKS}

Merrill Warkentin et al. [17] have highlighted the position of information in the management of supply chain relationships. It has described that the various qualities of information such as accuracy, appropriateness and consistency and has examined the relative importance of these in three e-commerce allow rising supply chain relationships. Mass-customization websites such as those offered by Dell.com are shown to be more-touch points that have a far greater impact on a firm's bottom-line than conventional touch points. This has reduced the number of touch points in a supply chain, and has promoted the acceptance of standards for data representation. Both of these in turn lower information irregularity and has improved the overall efficiency of the supply chain. Finally, their paper has described the rise of new marketplace models and the resulting new players and information flows.

Charles Bonomo [18] has conversed that the knowing which products to predict and when to keep safety stock is a serious situation of managing customer and supplier risk in a supply chain. Their work has provided some precious approach into the complex world of high-tech distribution and it has given a greater appreciation for the daily challenges.

Sanchoy K. Das et al. [8] offered a method for building an E-Market and a type to support the supplier selection decision. The manufacturer uses E-Market method which is used to obtain two key measures to obtain the suppliers performance estimation and thus gives sufficient guarantee to give a supply order, included by the type of the Vendor Performance History database. An Intelligent Vendor Selection model is also offered in addition to the given E-Market suggestion and approved a supply policy. Within the E-Market negotiation pattern this model was developed as a mixed integer program and solved.

Kefeng Xu et. al. [11] examined that a complete pooling on the isolated basis of demand correlation rarely favors through claiming the partial pooling of customers. Initially within the supply chain the management of inventory was discussed where risk-pooling was considered explicitly. Then theoretically they declared that partial pooling can dominate. The assured strength to check the correlation matrices is presented through this technique.

Ioannis Kontogounis et al [13] offered a mechanism which is robust, highly-adaptable and easily configurable which is capable with all SCM surfaces, from material procurement and inventory management to goods production and shipment. To crash-test the agent the trading agent competition SCM game is used which is one of the most challenging in SCM environments. Along with this, Mertacor and its main architectural primitives, a general idea of the TAC SCM environment and the performance of Mertacor were discussed.

The cumulative of two interrelated demands by utilizing the bivariate VAR(1) time series model as a study vehicle was examined by Argon Chen et al. [10]. It is visualized that the cumulative time series of two VAR (1) time series is equal to the sum of two $\mathrm{AR}(1)$ time series was presented. The properties cumulative time series was examined and the rules for beginners to establish proper aggregation and the approaches to predict were offered in addition.

Real Carbonneau et al [12] offered more conventional method to compare the performance of the new machine learning based forecasting techniques. A conventional representative set and ML-based techniques is applied to the demand data to compare the accuracy of the methods.

With the arrival of open standards and Internet technologies, the number of sellers who can participate in online exchanges is greatly increased. Subhajyoti Bandyopadhyay et al. [19] have started the competition between identical sellers competing for the same business, and it has found that there exists mixed-strategy balance in prices. Their results have helped them to understand the dynamics between a seller's capacity and their reason to participate in a sale.

Tatavarthy Srinivas Rao Balkrishna Rao et al. [20] have discussed that the problem was in selecting best suppliers among large numbers of suppliers who are contributing various raw materials with different slab rates for certain quantities. Their novel analysis for best suppliers based on GA has performed efficiently in choosing the best suppliers so that all the manufacturers are satisfied with the provided cost effective raw materials with best slab rates as well as the quantities which are closer to the aggregated demand. Their analysis has performed well in reaching the final meaning of satisfying the buyers (manufacturers) by providing its assistance to the web based agent.

Sreekumar and S. S. Mahapatra [21] have used a fuzzy method to deal with the supplier selection problem in supply chain. The method was based on hierarchical multiple criteria decision making (MCDM) using fuzzy approach to select suitable supplier. In such type of decision making problems, all the decision makers are assumed to be equally important resulting in not practical aggregation of decision. Therefore, an analytic hierarchy process (AHP) like procedure based on Eigen value has been proposed to derive the weight ages of decision makers. Then, weight ages of decision makers are included with fuzzy decision making example to arrive at healthy selection of suppliers in SCM. The methodology has been established with the help of a case study in a steel plant.

\section{The Proposed Analysis Of Optimal SupPliers With Better Purchasing Periods Supporting Web Based AGENT}

In the field of material demand aggregation, the manufacturers face a great demand for a variety of raw materials. And these raw materials are likely to be supplied by different suppliers at different costs. They also opt to offer slab rates for certain amount of raw materials. But the slab rate and the quantity for which the slab rate is offered differ from one supplier to another. Mean while, the periods of requirements for the raw materials also varies from one manufacturer to another. For instance, one manufacturer 
may be in need of raw materials within the tenth of a month and another manufacturer may be in the want of the same raw materials within the fifth. Probably the demand placing by a manufacturer for any raw materials also varies. If it is preferred to buy the raw materials beforehand to enjoy high slab rate, certain manufacturers will be affected because of the high inventory costs incurred as their requirement periods of raw materials will be more. Similarly, if it is suggested to purchase the raw materials just in time in order to avoid the inventory costs, the manufacturers may miss the benefits of high slab rates.

Under these crucial circumstances, web based agents are having the responsibility of analyzing the periods of purchasing of raw materials for each manufacturer and to select the better period for all manufacturers to purchase the raw materials. So that the manufacturers can enjoy the benefits of slab rates and they can also minimize the inventory costs so that the manufacturers can get cost-effective raw materials. For this purpose of supplying cost-effective raw materials to all the manufacturers, we propose an approach which selects the optimal period for all the manufacturers to buy the raw materials and also gives provision for suppliers to supply raw materials at low cost.

The novel analysis for selecting optimal periods of purchasing of raw materials by the manufacturers is illustrated in the Fig. 1.

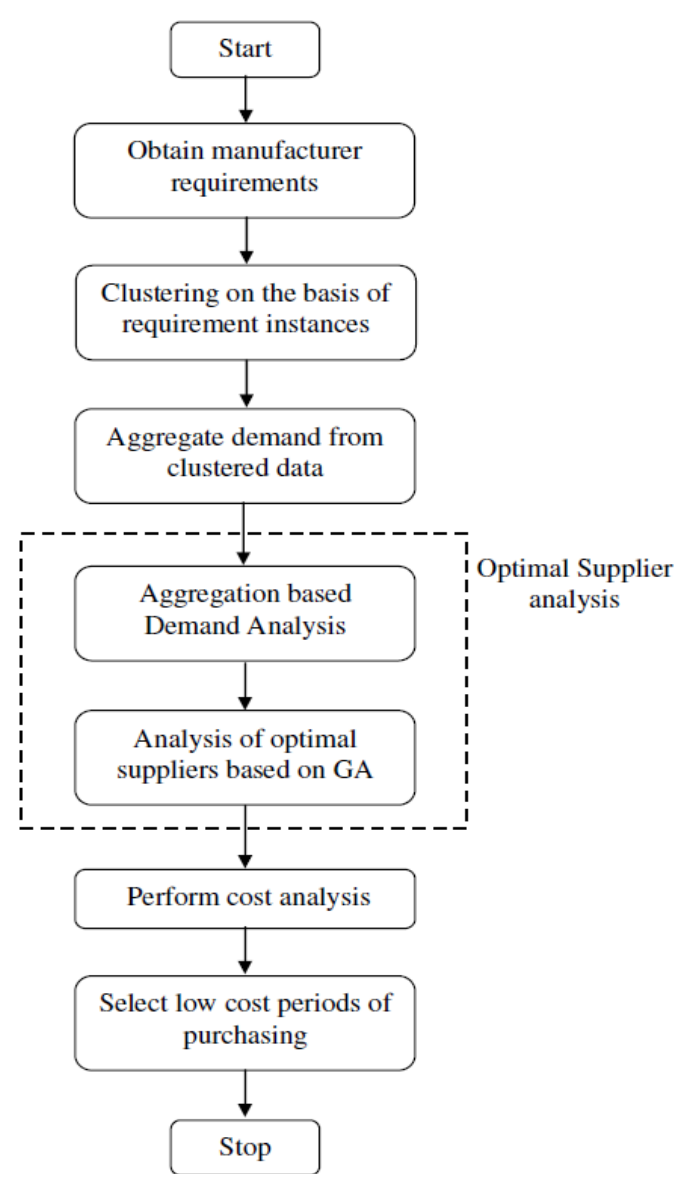

Fig. 1: Flow chart depicting the proposed analysis of optimal suppliers with better purchasing periods.

As depicted clearly, we should have a database which contains the requirements of all the manufacturers, their requirement date and the amount required in all the raw materials. Then as per the requirement date of each manufacturer, a clustering process will be done to obtain the different combinations of manufacturers followed by the aggregation based on the demand of raw materials for each cluster combinations. Then optimal suppliers will be identified for each aggregated demand using the optimal suppliers analysis based on GA [20]. After that a cost analysis will be performed for each cluster of period and finally the period of purchasing which offers the lowest cost is identified.

To conduct an analysis for selecting better purchasing period, we are in a need to maintain a database which will hold all the information about the raw materials which are in demand for all the manufacturers. It is likely to contain the demand level of raw materials, requirement duration of raw materials for all the manufacturers, the list of suppliers, the raw materials supplied by the suppliers, the slab rates offered by each supplier and the amount for which the slab rates are offered.

Consider, that there are $n$ number of manufacturers in demand of raw materials and then it can be represented as

$$
M=\left[\begin{array}{llll}
m_{1} & m_{2} & \cdots & m_{n}
\end{array}\right]
$$

As each supplier is prepared to supply different number of raw materials, we extract the manufacturers who require of same kind of raw materials. Hence if it is considered as all the $n$ number of manufacturers are in the need of the same kind of raw materials and each manufacturer requires the raw materials at a certain quantity, the representation can be done as

$$
M_{r}=\left[\begin{array}{l}
M_{r_{1}} \\
M_{r_{2}} \\
\vdots \\
M_{r_{n}}
\end{array}\right]=\left[\begin{array}{cccc}
Q_{m_{1}}^{(1)} & Q_{m_{1}}^{(2)} & \cdots & Q_{m_{1}}^{(p)} \\
Q_{m_{2}}^{(1)} & Q_{m_{2}}^{(2)} & \cdots & Q_{m_{2}}^{(p)} \\
\vdots & & & \\
Q_{m_{n}}^{(1)} & Q_{m_{n}}^{(2)} & \cdots & Q_{m_{n}}^{(p)}
\end{array}\right]
$$

Here, $M_{r}$ represents the amount of raw materials required by all the manufacturers, $Q_{m_{i}}^{(j)}$ represents the quantity of $j^{\text {th }}$ raw material needed by $i^{\text {th }}$ manufacturer, where $i=1,2,3, \cdots, n$ and $j=1,2,3, \cdots, p$. Every manufacturer is under the requirement of raw materials within a certain instant of time and the period for which the manufacturers are in demand of raw materials can be represented as follows 


$$
I_{r}=\left[\begin{array}{l}
I\left(M_{r_{1}}\right) \\
I\left(M_{r_{2}}\right) \\
\vdots \\
I\left(M_{r_{n}}\right)
\end{array}\right]=\left[\begin{array}{cccc}
I_{m_{1}}^{\left(q_{1}\right)} & I_{m_{1}}^{\left(q_{2}\right)} & \cdots & I_{m_{1}}^{\left(q_{p}\right)} \\
I_{m_{2}}^{\left(q_{1}\right)} & I_{m_{2}}^{\left(q_{2}\right)} & \cdots & I_{m_{2}}^{\left(q_{p}\right)} \\
\vdots & & & \\
I_{m_{n}}^{\left(q_{1}\right)} & I_{m_{n}}^{\left(q_{2}\right)} & \cdots & I_{m_{n}}^{\left(q_{p}\right)}
\end{array}\right]
$$

The vector given in the equation (3) is provides the instant of requirement of the raw materials for all the $n$ manufacturers. $I_{m_{i}}^{\left(q_{j}\right)}$ is the instant of time within which the $j^{\text {th }}$ raw material is required for the $i^{\text {th }}$ manufacturer. Based on this period of requirement, some sets of combination will be made and clustered.

\section{A. Clustering}

Clustering is done based on the periods of requirement of all the raw materials. It clusters all those manufacturers who require raw materials at the same instant of time. Let us assume that the manufactures requires raw materials at $l$ different instants of time, and on the basis of these instants clustering will be done. Then the clustered data will be represented as

$$
\left[\begin{array}{l}
I_{c_{1}} \\
I_{c_{2}} \\
\vdots \\
I_{c_{l}}
\end{array}\right]=\left[\begin{array}{cccc}
M_{c_{1}}^{(1)} & M_{c_{1}}^{(2)} & \cdots & M_{c_{1}}^{(p)} \\
M_{c_{2}}^{(1)} & M_{c_{2}}^{(2)} & \cdots & M_{c_{2}}^{(p)} \\
\vdots & & & \\
M_{c_{l}}^{(1)} & M_{c_{l}}^{(2)} & \cdots & M_{c_{l}}^{(p)}
\end{array}\right]
$$

In equation (4), $I_{c_{k}}$ is the period of requirement of the raw material which forms a cluster $k$, where $k=1,2,3, \cdots, l . M_{{ }_{k}}^{(j)}$ is the manufacturers vector who are in need of the raw material $j$ on $I_{c}{ }_{k}{ }^{t h}$ instant of time and then the vector can be formed as follows

$$
M_{c_{k}}^{(j)}<<m_{i} \quad ; \text { if } I_{m_{i}}^{\left(q_{j}\right)}=I_{c_{k}}
$$

where,

$$
\begin{gathered}
i=1,2,3, \cdots, n \\
j=1,2,3, \cdots, p \\
k=1,2,3, \cdots, l
\end{gathered}
$$

From the represented cluster, different sets of manufacturers can be obtained. These different sets of information will be taken for analysis. The sets thus obtained from the clustered information is given as

$$
\left\{S_{1}\right\}=\left\{M_{c_{1}}^{(j)}, M_{c_{2}}^{(j)}, \cdots \cdots, M_{c_{l}}^{(j)}\right\}
$$

$$
\begin{gathered}
\left\{S_{2}\right\}=\left\{\left\{M_{c_{1}}^{(j)}\right\},\left\{M_{c_{2}}^{(j)}, \cdots \cdots, M_{c_{l}}^{(j)}\right\}\right\} \\
\left\{S_{3}\right\}=\left\{\left\{M_{c_{1}}^{(j)}\right\},\left\{M_{c_{2}}^{(j)}\right\}, \cdots \cdots, M_{c_{l}}^{(j)}\right\}
\end{gathered}
$$

$$
\left\{S_{l}\right\}=\left\{\left\{M_{c_{1}}^{(j)}\right\},\left\{M_{c_{2}}^{(j)}\right\}, \cdots \cdots,\left\{M_{c_{l}}^{(j)}\right\}\right\}
$$

As derived from the equation (6), the number of manufacturers in each cluster for a particular raw material is equal to the total number of manufacturers $n$ and this can be given as

$$
\sum_{j=1}^{p} \sum_{k=1}^{l}\left|M_{c_{k}}^{(j)}\right|=n / p
$$

In equation (7), each set is will have some subsets except $\left\{S_{1}\right\}$. Particularly, the $l^{\text {th }}$ set will have $l$ subsets. Each subset will have a vector of manufacturers belonging to the cluster who are in need of $p$ raw materials.

\section{B. Aggregation of demand}

Subsequently, the demand acquired from the subset of each set will be determined and the demand thus obtained will be maintained in a database. The database maintained will have the aggregated demand of different combinations of manufacturers.

The demand can be aggregated as follows

$$
D_{s_{1}}=\left\{\sum_{a=1}^{l} \sum_{b}^{\left|M_{c_{a}}^{(j)}\right|} Q_{m_{b}}^{(j)}\right.
$$




$$
D_{s_{3}}=\left\{\begin{array}{cc}
D_{s_{31}}=\sum_{b}^{\left|M_{c_{1}}^{(j)}\right|} Q_{m_{b}}^{(j)} & \begin{array}{l}
\text { initialize the chromosomes in a random } \\
\text { chromosome is composed of 'p' number of } \\
\text { chromosome length is } p \text { ) and every gene repr }
\end{array} \\
D_{s_{32}}=\sum_{b}^{\left|M_{c 2}^{(j)}\right|} Q_{m_{b}}^{(j)} & \begin{array}{l}
\text { value of a definite raw material. The chromos } \\
\text { takes the form, }
\end{array} \\
D_{s_{33}}=\sum_{a=3}^{l} \sum_{b}^{\left|M_{c_{a}}^{(j)}\right|} Q_{m_{b}}^{(j)} & X(y)=\left\{x_{1}^{(y)} x_{2}^{(y)} x_{3}^{(y)} \cdots \cdots x_{p}^{(y)}\right\}
\end{array}\right.
$$$$
D_{s_{l}}=\left\{\begin{array}{c}
D_{s_{l 1}}=\sum_{b}^{\left|M_{c 1}^{(j)}\right|} Q_{m_{b}}^{(j)} \\
D_{s_{l 2}}=\sum_{b}^{\left|M_{c 2}^{(j)}\right|} Q_{m_{b}}^{(j)} \\
\vdots \\
D_{s_{l l}}=\sum_{b}^{M_{c l}^{(j)} \mid} Q_{m_{b}}^{(j)}
\end{array}\right.
$$

The equations (8.1, 8.2, 8.3 and 8.4) describe the aggregated demand of each set of the cluster combination. According to equation (8) $D_{s_{i}}$ will consist of $i$ different levels of aggregated demand. Hence the total number of individual demand levels after the process of demand aggregation will be

\section{Total no. of aggregated demand}

$$
\text { levels } T=(l(l+1)) / 2
$$

The set values having the aggregated demand can be represented as

$$
D_{s}=\left\{\begin{array}{l}
\left\{D_{s_{1}}\right\}\left\{D_{s_{21}}, D_{s_{22}}\right\}\left\{D_{s_{31}}, D_{s_{32}}, D_{s_{33}}\right\} \\
\cdots \cdots\left\{D_{s_{l 1}}, D_{s_{l 2}}, D_{s_{l 3}}, \cdots D_{s_{l l}}\right\}
\end{array}\right\}
$$

These demand values will be subjected to optimal supplier's analysis which will provide the supplier for each raw material who can provide the raw material in a cost effective manner. This can be done by the process of optimal suppliers analysis based on GA [20] and it is discussed next.

\section{Analysis for optimal suppliers based on GA}

The pre-analysis section of optimal suppliers based on GA, i.e., Aggregation based Demand Analysis is done so that we have calculated the total demand for different combinations of clusters. The set values of aggregated demand are given in the equation (10). The final step of indexing the aggregated demand will be done as in the Aggregation based Demand Analysis. Then the Analysis of optimal suppliers based on GA will be performed for each demand level as follows

Initialize Chromosome: To start with, we initialize the value of the optimization factor to one. The next process is to initialize the chromosomes in a random manner. Every chromosome is composed of 'p' number of genes (i.e. the chromosome length is $p$ ) and every gene represents an index value of a definite raw material. The chromosome attained

Every gene of the chromosome is produced by employing the below formulation:

$$
x_{j}^{(y)}=1+\left(r \%\left|I_{r_{j}}\right|\right) ; j=1,2, \ldots, p
$$

where,

$r$ is an arbitrary integer

$x_{j}^{(y)}$ is the $j^{\text {th }}$ gene of $y^{\text {th }}$ chromosome.

As a result, $z$ number of chromosomes will be arbitrarily generated. Each gene possesses an index value which denotes a definite quantity of the raw material and its associated slab rate.

Determine Fitness: Next to the process of chromosome generation, all these generated chromosomes will be evaluated using a fitness function. The fitness function of the proposed analysis is given by

$$
f(u)=\frac{O_{f}}{\frac{1}{p} \sum_{j=1}^{p} s_{j}^{(u)}} ; u=1,2, \ldots \ldots, z
$$

where $s_{j}^{(u)}$ is the slab rate indexing by $j^{t h}$ gene of $u^{t h}$ chromosome.

At the end, the fitness values of the $z$ numbers of chromosomes can be obtained. Then the chromosomes will be subjected to genetic operations.

Crossover: Subsequently crossover operation is performed on the chromosomes. Crossover can be defined as a genetic operation by which every pair of chromosome yields a child or two children. For any chromosome of $p$ length, there will be $(t-1)$ points and then the crossover point $C_{p}$ can be found as given below

$$
C_{p}=t / 2
$$

For the case considered, we employ the single point crossover, with the crossover point located at $t / 2$. With single point crossover, the genes of the parent chromosomes located at the right of $C_{p}$ get interchanged to yield the children.

Mutation: The crossover operation is followed up with 
another genetic operation, mutation. The mutation operation is performed on the children and the mutation technique we employ here changes the genes of the child chromosome within itself to get a new chromosome. The new chromosome obtained is shown by

$$
\begin{gathered}
X^{n e w}(y)=\left\{x_{n e w_{1}}^{(y)} x_{n e w_{2}}^{(y)} \cdots x_{n e w_{p}}^{(y)}\right\} ; \\
y=z+1, z+2, \ldots \ldots .2 z
\end{gathered}
$$

Because of the constraint that the index value of each chromosome should not exceed the original index specified in the database, the confinement of the entirely new chromosome obtained after mutation is verified.

Subsequently, the same fitness function used to evaluate the fitness of the chromosomes is applied to the new set of chromosomes. Thereby we have obtained a $2 z$ numbers of chromosomes and their corresponding fitness values at this point of time.

Selection of better chromosomes: The next step is to spot the superior $z$ numbers of chromosomes, by the application of a selection operation. The selection operation selects those chromosomes having minimum fitness values. Thus we have obtained $z$ numbers of superior chromosomes from the $2 z$ numbers of chromosomes. Expecting the accomplishment of the termination condition, the process of crossover, mutation, fitness evaluation and selection are performed repeatedly on the newly obtained chromosomes. The termination condition employed in our work is the Attainment of maximum number of iterations. The execution procedure will be terminated after utmost iterations are reached by the process.

The resultant chromosome obtained will act as index for suppliers for every raw material and their corresponding slab rates for a certain quantity. The suppliers thus got from the analysis can provide the raw materials to all the manufacturers in a cost-effective manner with optimal slab rates.

$$
\begin{aligned}
& C_{s_{1}}=\frac{1}{p} \sum_{j=1}^{p}\left[\sum_{b}^{\left|M_{c_{1}}^{(j)}\right|} Q_{m_{b}}^{(j)} c_{r_{j}}\left(S_{r_{\text {opt }}}\left(D_{s_{1}}^{(g)}(j)\right)\right)+\sum_{b}^{\left|M_{c_{2}}^{(j)}\right|} Q_{m_{b}}^{(j)}\left(\left(\left(I_{c_{2}}-I_{c_{1}}\right) \times h_{c}(b)\right)+c_{r_{j}}\right)\left(S_{r_{\text {opt }}}\left(D_{s_{2}}^{(g)}(j)\right)\right)+\cdots\right. \\
& \left.\left.\left|\sum_{b}^{M} Q_{m_{b}}^{(j)}\right|\left(\left(I_{c_{l}}-I_{c_{1}}\right) \times h_{c}(b)\right)+c_{r_{j}}\right)\left(S_{r_{o p t}}\left(D_{s_{l}}^{(g)}(j)\right)\right)\right] \\
& C_{s_{2}}=\frac{1}{p} \sum_{j=1}^{p}\left[\mid \sum_{b}^{\left|M_{c_{1}}^{(j)}\right|} Q_{m_{b}}^{(j)} c_{r_{j}}\left(S_{r_{o p t}}\left(D_{s_{1}}^{(g)}(j)\right)\right)+\sum_{b}^{M_{c_{2}}^{(j)}} Q_{m_{b}}^{(j)} c_{r_{j}}\left(S_{r_{o p t}}\left(D_{S_{2}}^{(g)}(j)\right)\right)+\right.
\end{aligned}
$$




$$
\begin{aligned}
& \sum_{b}^{M_{c_{3}}^{(j)}} \mid Q_{m_{b}}^{(j)}\left(\left(\left(I_{c_{3}}-I_{c_{2}}\right) \times h_{c}(b)\right)+c_{r_{j}}\right)\left(S_{r_{o p t}}\left(D_{s_{3}}^{(g)}(j)\right)\right)+\cdots \\
& \left.\left|\sum_{b}^{M_{c l}^{(j)}}\right| Q_{m_{b}}^{(j)}\left(\left(\left(I_{c_{l}}-I_{c_{2}}\right) \times h_{c}(b)\right)+c_{r_{j}}\right)\left(S_{r_{o p t}}\left(D_{s_{l}}^{(g)}(j)\right)\right)\right]
\end{aligned}
$$

Like wise,

$$
C_{s_{l}}=\frac{1}{p} \sum_{j=1}^{p}\left[\sum_{b}^{\left|M_{c_{1}}^{(j)}\right|} Q_{m_{b}}^{(j)} c_{r_{j}}\left(S_{r_{o p t}}\left(D_{s_{1}}^{(g)}(j)\right)\right)+\sum_{b}^{M_{c_{2}}^{(j)}} Q_{m_{b}}^{(j)} c_{r_{j}}\left(S_{r_{o p t}}\left(D_{s_{2}}^{(g)}(j)\right)\right)+\cdots \sum_{b}^{M_{c_{l}}^{(j)}} Q_{m_{b}}^{(j)} c_{r_{j}}\left(S_{r_{o p t}}\left(D_{s_{l}}^{(g)}(j)\right)\right)\right]
$$

where hc-holding $\cos t$

$$
c_{r_{j}}-\cos t \text { of } j^{\text {th }} \text { raw material }
$$

$Q_{m_{b}}^{(j)}$ is the quantity of $j^{\text {th }}$ raw material required by $b^{\text {th }}$ manufacturer

$$
S_{r_{\text {opt }}}\left(D_{s_{1}}^{(g)}(j)\right) \text { is the optimal slab rate offered by the }
$$
supplier for the demand of $l^{\text {th }}$ cluster which was identified by the optimal suppliers analysis for the $j^{\text {th }}$ raw material.

Thus we can obtain the costs for each cluster and the clusters are analyzed to get the minimum cost ie., the best cost and the corresponding cluster is called the best cluster. On the basis of the chosen best cluster, the web based agent will provide suggestions for all the manufacturers for purchasing the raw materials in optimal time. If a cluster set $i$ is chosen as the best cluster then the suggestions of the web based agent will be as follows

$M_{c_{1}}^{(j)}$ manufacturers to purchase at the instant of time $I_{c_{1}}$

$M_{c_{2}}^{(j)}$ manufacturers to purchase at the instant of time $I_{c_{2}}$

$M_{c_{i-1}}^{(j)}$ manufacturers to purchase at the instant of time $I_{c_{i-1}}$

$M_{c_{i}}^{(j)}, M_{c_{i+1}}^{(j)}, \ldots M_{c_{l}}^{(j)}$ manufacturers to purchase at the instant of time $I_{c_{i}}$

Thus optimal periods of purchasing for all the manufacturers will be suggested by the web based agent with the aid of proposed analysis for selection of optimal period of purchasing so that all the manufacturers can enjoy optimal slab rates as per their requirement level of raw materials as well as less inventory costs.

\section{IMPLEMENTATION RESULTS}

The proposed analytical model for identifying the better period for purchasing the raw materials to the manufacturers has been implemented in the platform of MATLAB (version MATLAB 7.4). Here, we have used ' 100 ' manufacturers, ' 3 ' raw materials ' $\mathrm{r} 1$ ', ' $\mathrm{r} 2$ ' and ' $\mathrm{r} 3$ ' and '4' suppliers. The manufacturers require raw materials at ' 3 ' different instant times, $15^{\text {th }}, 20^{\text {th }}, 25^{\text {th }}$ of month. The Table 1 has the information about the manufacturers and the periods at which the raw materials are required. Just a sample of data is

\begin{tabular}{|c|c|}
\hline \multicolumn{2}{|c|}{ Raw material $\mathbf{r} 1$ requirement } \\
\hline \begin{tabular}{|c|} 
Manufacturer \\
ID
\end{tabular} & $\begin{array}{c}\text { Period of } \\
\text { requirement }\end{array}$ \\
\hline 21 & 15 \\
\hline 22 & 25 \\
\hline 23 & 25 \\
\hline 24 & 15 \\
\hline 25 & 20 \\
\hline 26 & 20 \\
\hline 27 & 15 \\
\hline
\end{tabular}
simulated here for the purpose of implementation is given in the Table 1.

TABLE (1.A): MANUFACTURER ID AND THE PERIOD OF REQUIREMENT OF THE RAW MATERIALS 'R1'

TABLE (1.B): MANUFACTURER ID AND THE PERIOD OF REQUIREMENT OF THE RAW MATERIALS ' $R 2$ '

Raw material $\mathbf{r} 2$ requirement

\begin{tabular}{|c||c|}
\hline Manufacturer ID & $\begin{array}{c}\text { Period of } \\
\text { requirement }\end{array}$ \\
\hline 1 & 15 \\
\hline 2 & 15 \\
\hline
\end{tabular}




\begin{tabular}{|c|c|}
\hline \multicolumn{2}{|c|}{ Raw material r2 requirement } \\
\hline Manufacturer ID & $\begin{array}{c}\text { Period of } \\
\text { requirement }\end{array}$ \\
\hline 3 & 15 \\
\hline 4 & 15 \\
\hline 5 & 15 \\
\hline 6 & 15 \\
\hline 7 & 25 \\
\hline 8 & 15 \\
\hline
\end{tabular}

TABLE (1.C): MANUFACTURER ID AND THE PERIOD OF REQUIREMENT OF THE RAW MATERIALS 'R3'

\begin{tabular}{|c|c|}
\hline \multicolumn{2}{|c|}{ Raw material r3 requiremen } \\
\hline \begin{tabular}{|c|} 
Manufacturer \\
ID \\
\end{tabular} & $\begin{array}{c}\text { Period of } \\
\text { requirement }\end{array}$ \\
\hline 1 & 25 \\
\hline 2 & 25 \\
\hline 3 & 25 \\
\hline 4 & 25 \\
\hline 5 & 25 \\
\hline 6 & 15 \\
\hline 7 & 20 \\
\hline 8 & 15 \\
\hline
\end{tabular}

As per the Table 1, the manufacturer having the ID ' 21 ' needs raw material " $r 1$ " within the date of $15^{\text {th }}$ and similarly the manufacturer having the ID ' 1 ' needs raw material " $\mathrm{r} 2$ ' within the date of $15^{\text {th }}$. The database having such kind of information have been maintained along with the database of the information about the suppliers, the raw materials which can be supplied by them, the slab rates offered by the ' 4 ' suppliers and the quantity to which the slab rates offers.

As ' 3 ' instants of time have been utilized for purchasing the raw materials, there are' 3 ' clusters. For that we have analyzed optimal suppliers and to obtain optimal slab rates offered by the suppliers. Then with the help of the slab rates the cost analysis will be done and thus we have obtained different costs to each raw material for each cluster and the cost thus obtained for the mentioned records are given in the Table 2.

TABLE 2: THE TOTAL COST OF EACH MATERIAL IS DETERMINED TO EACH CLUSTER AND ALSO THE AVERAGE COST OF EACH CLUSTER.

\begin{tabular}{|c|c|c|c|c|}
\hline $\begin{array}{c}\text { Clusters } \\
\text { based on } \\
\text { the period } \\
\text { of } \\
\text { requiremen } \\
\mathrm{t}\end{array}$ & $\begin{array}{c}\text { Raw } \\
\text { 'r1' }\end{array}$ & $\begin{array}{c}\text { Raw } \\
\text { material } \\
\text { 'r2' }\end{array}$ & $\begin{array}{c}\text { Raw } \\
\text { material } \\
\text { 'r3' }\end{array}$ & $\begin{array}{c}\text { Average } \\
\text { cost of the } \\
\text { cluster }\end{array}$ \\
\hline Cluster 1 & 27819 & 60102 & 41706 & 43209 \\
\hline Cluster 2 & 31392 & 21654 & 28108 & 27051 \\
\hline Cluster 3 & 26226 & 19134 & 23904 & 23088 \\
\hline
\end{tabular}

The Table 2 given here has the information about the cost of the raw material if it is purchased in the period mentioned in cluster 1,2 and 3 .

The cluster which offers minimum cost of purchasing is the best cluster. In our implementation we found that the cluster 3 is the best cluster. Hence, the suggestion will look as in the Table 3. Just a few output data is given in the Table 3.

TABLE 3 (A): THE MANUFACTURERS AND THE RAW MATERIALS WHICH ARE SUGGESTED TO PURCHASE AT THE DATE OF 15

\begin{tabular}{|c|c|c|}
\hline $\begin{array}{c}\text { Sr. } \\
\text { No. }\end{array}$ & $\begin{array}{c}\text { Manufacture } \\
\text { r ID }\end{array}$ & $\begin{array}{c}\text { Suggested } \\
\text { raw } \\
\text { material to } \\
\text { purchase }\end{array}$ \\
\hline 1 & 4 & R1 \\
\hline 2 & 5 & R1 \\
\hline 3 & 7 & R1 \\
\hline 4 & 1 & R2 \\
\hline 5 & 2 & R2 \\
\hline 6 & 3 & R2 \\
\hline 7 & 4 & R3 \\
\hline 8 & 6 & R3 \\
\hline 9 & 8 & R3 \\
\hline
\end{tabular}

Table 3 (A) gives the details about the manufacturers who are recommended to purchase the corresponding raw materials during $15^{\text {th }}$ in a month and the slab rate offered for each raw material while purchasing at that period is as follows

Slab rate $9 \%$ for Raw material ' $\mathrm{r} 1$ ' when it is purchased from supplier having ID ' 2 '

Slab rate $4 \%$ for Raw material ' $\mathrm{r} 2$ ' when it is purchased from supplier having ID ' 2 '

Slab rate $8 \%$ for Raw material ' $r 3$ ' when it is purchased from supplier having ID ' 2 '

TABLE 3 (B): THE MANUFACTURERS AND THE RAW MATERIALS WHICH ARE SUGGESTED TO PURCHASE AT THE DATE OF 20

\begin{tabular}{|c|c|c|}
\hline $\begin{array}{c}\text { Sr. } \\
\text { No. }\end{array}$ & $\begin{array}{c}\text { Manufacture } \\
\text { r ID }\end{array}$ & $\begin{array}{c}\text { Suggested } \\
\text { raw material } \\
\text { to purchase }\end{array}$ \\
\hline 1 & 3 & R1 \\
\hline 2 & 6 & R1 \\
\hline 3 & 10 & R1 \\
\hline 4 & 19 & R2 \\
\hline 5 & 26 & R2 \\
\hline 6 & 27 & R2 \\
\hline 7 & 9 & R3 \\
\hline 8 & 24 & R3 \\
\hline 9 & 27 & R3 \\
\hline
\end{tabular}

Table 3 (B) gives the details about the manufacturers who are recommended to purchase the corresponding raw materials during $20^{\text {th }}$ in a month and the slab rate offered for each raw material while purchasing at that period is as follows

Slab rate $9 \%$ for Raw material ' $\mathrm{r} 1$ ' when it is purchased from supplier having ID ' 2 ' 
Slab rate $4 \%$ for Raw material ' $\mathrm{r} 2$ ' when it is purchased from supplier having ID ' 2 '

Slab rate $8 \%$ for Raw material ' $r 3$ ' when it is purchased from supplier having ID ' 2 '

TABLE 3 (C): THE MANUFACTURERS AND THE RAW MATERIALS WHICH ARE

\begin{tabular}{|} 
SUGGESTED TO PURCHASE AT THE DATE OF 25 \\
$\begin{array}{c}\text { Sr. } \\
\text { No. }\end{array}$ & $\begin{array}{c}\text { Manufacture } \\
\text { r ID }\end{array}$ & $\begin{array}{c}\text { Suggested } \\
\text { raw material } \\
\text { to purchase }\end{array}$ \\
\hline 1 & 9 & R1 \\
\hline 2 & 17 & R1 \\
\hline 3 & 18 & R1 \\
\hline 4 & 10 & R2 \\
\hline 5 & 11 & R2 \\
\hline 6 & 12 & R2 \\
\hline 7 & 13 & R3 \\
\hline 8 & 14 & R3 \\
\hline 9 & 16 & R3 \\
\hline
\end{tabular}

Table 3 (C) gives the details about the manufacturers who are recommended to purchase the corresponding raw materials during $15^{\text {th }}$ in a month and the slab rate offered for each raw material while purchasing at that period is as follows

Slab rate 9\% for Raw material ' $\mathrm{r} 1$ ' when it is purchased from supplier having ID ' 2 '

Slab rate 4\% for Raw material ' $\mathrm{r} 2$ ' when it is purchased from supplier having ID ' 4 '

Slab rate $8 \%$ for Raw material ' $\mathrm{r} 3$ ' when it is purchased from supplier having ID ' 2 '

Thus each manufacturer is recommended to purchase certain raw materials at particular period so that the manufacturer will not be suffered by too much of inventory cost as well as they can enjoy with good slab rates.

\section{V.CONCLUSION}

The web based material demand aggregation, which is an interesting research area of supply chain management works actively with the objective of fulfilling the material demands of the buyers. Specifically, our work aims to satisfy the manufacturer's requirements at an optimal cost. Obviously, every manufacturer is in need of raw materials at different instants of time and the raw material supplier's are likely to offer a specific slab rates for certain quantity of raw materials in the materials market. Hence, it is difficult to identify the optimal period of purchasing the raw materials for all the manufacturers. The proposed analytical model overcomes this challenge and works well by extracting the better periods of purchasing the raw materials for all the manufacturers so that the manufacturers can enjoy a reasonable slab rate as well as they can avoid high inventory costs. This results in purchasing of the raw materials by all the manufacturers in an effective cost. With the assistance of our analytical model, the web based agent can guide all the manufacturers by providing better periods to purchase the raw materials so that the manufacturers can reduce the cost of purchasing as well as maintenance for every raw material. Hence, by utilizing the model, the web based agent can accomplish the goal of material demand aggregation and thus it will lay cornerstone for an effective supply chain.

\section{REFERENCES}

[1] Alfonso Sarmiento, Luis Rabelo, Ramamoorthy Lakkoju, Reinaldo J. Moraga, "Stability analysis of the supply chain by using neural networks and genetic algorithms," Proceedings of the 39th conference on Winter simulation, pp. 1968-1976, December 09-12, Washington D.C, 2007.

[2] J. A. Joines, D. Gupta, M. A. Gokce, R. E. King; and M. G. Kay, "Supply chain multi-objective simulation optimization," in Proceedings of the 2002 Winter Simulation Conference, pp.1306-1314, 2002.

[3] P.Radhakrishnan, V.M.Prasad and M. R. Gopalan, "Inventory Optimization in Supply Chain Management using Genetic Algorithm," International Journal of Computer Science and Network Security, Vol. 9 , No. 1, pp. 33-40, 2009.

[4] J. Sudhir Ryan Daniel and Chandrasekharan Rajendran, "A simulation-based genetic algorithm for inventory optimization in a serial supply chain", International Transactions on Operational Research, Vol. 12, pp. 101-127, 2005

[5] Beamon BM, "Supply chain design and analysis: models and methods", International Journal of Production Economics, Vol. 55, No. 3, pp. 281-294, 1998.

[6] D. Pardoe and P. Stone, "An autonomous agent for supply chain management," In G. Adomavicius and A. Gupta, editors, Handbooks in Information Systems Series: Business Computing. Elsevier, 2007

[7] Keah Choon Tan, "A framework of supply chain management literature," European Journal of Purchasing \& Supply Management, Vol. 7, pp. 39-48, 2001.

[8] Sanchoy K. Das and Hossam Shahin, "Models for supply chain vendor selection in e-markets," Journal of the Chinese Institute of Industrial Engineers, Vol. 20, No. 3, pp. 231-239, 2003.

[9] Ge Wang, Samuel H. Huang, and John P. Dismukes, "Product-driven supply chain selection using integrated multi-criteria decision-making methodology," Journal of International Production Economics, Vol.91, pp. $1-15,2004$

[10] Argon Chen, C.H. Hsu and J. Blue, "Demand planning approaches to aggregating and forecasting interrelated demands for safety stock and backup capacity planning," International Journal of Production Research, Vol. 45, No. 10, pp. 2269-2294, 2007.

[11] Kefeng Xu, Philip T. Evers, "Managing single echelon inventories through demand aggregation and the feasibility of a correlation matrix," Computers and Operations Research, Vol. 30, No. 2, pp. 297 - 308, 2003.

[12] Real Carbonneau, Rustam Vahidov and Kevin Laframboise, "Machine learning-Based Demand forecasting in supply chains," International Journal of Intelligent Information Technologies, Vol. 3, No. 4,pp. 40-57, 2007.

[13] Ioannis Kontogounis, Kyriakos C. Chatzidimitriou, Andreas L.Symeonidis and Pericles A. Mitkas, "A Robust Agent Design for Dynamic SCM Environments," In Fourth Hellenic Conference on Artificial Intelligence, Heraklion, Greece, 2006.

[14] Sunil Chopra, Peter Meindl, "Supply Chain Management," Pearson Education, International Edition, 3rd Edition, 2008, ISBN13: 9780132086080 ISBN10: 0132086085

[15] Alonso J. Juvinao Carbono, Ivan F. M. Menezes, Luiz Fernando Martha, "Mooring Pattern Optimization using Genetic Algorithms," 6th World Congresses of Structural and Multidisciplinary Optimization, pp. 1-9, 30 May - 03 June, Brazil, 2005.

[16] A.John Sanjeev Kumar, J.Arunadevi, V.Mohan, "Intelligent Transport Route Planning Using Genetic Algorithms in Path Computation Algorithms," European Journal of Scientific Research, Vol. 25, No. 3 , pp.463-468, 2009.

[17] Merrill Warkentin, Ravi Bapna and Vijayan Sugumaran "The Role Of Mass Customization In Enhancing Supply Chain Relationships In B2c E-Commerce Markets", Journal of Electronic Commerce Research, Vol. 1, No. 2,pp.45-52, 2000.

[18] Charles, Bonomo, "Forecasting from the center of the supply chain", Journal of Business Forecasting - Methods and Systems, vol.22 no.1 pp.3-9, April 2003, ISSN:02786087 http://www.ibf.org/Downloads/Spring_2003_Article.pdf

[19] Subhajyoti Bandyopadhyay, John M. Barron and Alok R. Chaturvedi, "Capacity and entry issues in online exchanges", European Journal of Operational Research, Vol.185 pp. 849-863, 2008.

[20] Tatavarthy Srinivas Rao Balkrishna Rao, Naidu and Mallikharjuna Babu,"A Novel and Efficient Approach for Materials Demand Aggregation using Genetic Algorithm", International Journal of Computer Science and Network Security, Vol.9, No.4,pp.203-212,April 2009 . 
[21] Sreekumar and S. S. Mahapatra, "A fuzzy multi-criteria decision making approach for supplier selection in supply chain management", African Journal of Business Management, Vol.3, No.4, pp.168-177, April 2009.

T Srinivas Rao received his B.E from College of Engineering, Sewagram, Wardha and M.Tech in industrial Engineering From Visvesraya National Institute of Technology, Nagpur in 1988 and 1997 respectively. He is currently pursuing the $\mathrm{PhD}$ degree from Visvesvaraya Technological University, belgaum. He is working closely under the supervision of Dr. N V R Naidu and Dr. K Mallikharjuna Babu. He has also served in various Mechanical industries from the period 1988 to 1994.At present he working as Assistant professor in the department of Mechanical Engineering with Amrita School of Engineering, Bangalore.

Dr N V R Naidu has received his B.E (Mechanical Engineering, 1980), M.Tech (Industrial Engineering, 1982), and Ph.D (Robust Engineering, 2003) from Sri. Venkateswara University, Tirupati, AP, India. Currently he is Professor and Head of Industrial Engineering and Management Department at M.S. Ramaiah Institute of Technology, Bangalore. He has a total teaching experience of 27 years and 1 year of experience in Industry. He has Presented / published 51 technical papers in various national and international conferences and referred journals. Also Authored 6 text books, guided about 60 live UG projects in the filed of Production, Industrial Engineering and Management. Currently he is guiding $5 \mathrm{Ph} . \mathrm{D}$ students in the areas of Production Management, Lean Manufacturing. He is als BOS Chairman for IP/IM/MA VTU 2007-2010. Chaired sessions in national \& international conferences - FAIM 2008 - USA, ICORAID and IIIE. Technical committee chairman for IIIE 48th National convention held at Bangalore in the year 2006. Faculty advisor of FSAE - 2008 RACE CAR CONTEST Formula SAE, Japan. Actively involved in a collaborative project titled "Life cycle cost estimation for defense equipment (LCCD)" CASSA - MSRIT, funded by DRDO, Bangalore.

Dr. K Mallikharjuna Babu did his B.Tech, M.Tech and PhD degrees From Bangalore University. $\mathrm{He}$ has a total of 24 years of teaching experience. Currently he is guiding $5 \mathrm{PhD}$ students. Also Authored 6 text books, guided about 60 live UG projects in the filed of Production, Industrial Engineering and Management. Currently he is guiding $5 \mathrm{Ph} . \mathrm{D}$ students in the areas of Production Management, Lean Manufacturing. He has presented many papers in the National \& International Journal. Currently he is the Principal for BMS college of Engineering, Bangalore. 